\title{
CHARACTERISATION OF EPOXY NANOCOMPOSITES REINFORCED BY POTASSIUM TITANATE WHISKER
}

\author{
WAN-TING SUN, HITOSHI TAKAGI \& ANTONIO N. NAKAGAITO \\ Tokushima University, Japan
}

\begin{abstract}
The mechanical and physical properties of potassium titanate whisker (PTW) reinforced epoxy nanocomposites have been studied to examine the contribution of PTW loading and surface modification effects on these properties. Tensile tests and micro-hardness measurements have been used to study the mechanical performance of epoxy-based nanocomposites reinforced with $1 \mathrm{wt} \%$ to $5 \mathrm{wt} \%$ of PTW. We found that the mechanical properties and micro-hardness of PTW-reinforced epoxy nanocomposites become higher than those of neat epoxy resin. Furthermore, the experimental results showed that the nanocomposites reinforced with silane-treated PTW have higher tensile strength and Young's modulus. The micro-hardness of the treated PTW nanocomposites also had higher values as compared with that of untreated PTW nanocomposites. These results indicate that the mechanical performances of the PTW/epoxy nanocomposites were controlled by the silane surface treatment. Scanning electron microscopy studies indicated that the fracture surface of the silane-treated PTW nanocomposite had better interfacial adhesion, as the PTWs were covered with matrix resin.
\end{abstract}

Keywords: potassium titanate whisker, nanocomposites, mechanical properties, micro-hardness, silane treatment.

\section{INTRODUCTION}

Recently, epoxy resins have increasingly gained much importance because of their wide range of applications in many fields such as coatings, electrical and electronic devices, casting resins, dipping compounds, moulding powders and fibre-reinforced plastics. Because of their high strength, versatility and excellent adhesion to a wide variety of surfaces, epoxy resins have gained wide acceptance by diverse users [1], [2]. In addition, epoxy resins have been considered the most popular matrix in polymer composite materials with potential use in various industrial applications such as vehicles and aerospace, due to their excellent chemical resistance, good electrical insulation, high dimensional stability, and outstanding mechanical performances [2], [3].

Over the past few years, many researchers have demonstrated that the mechanical properties of whisker-reinforced epoxy-based nanocomposites can be improved compared to the pristine epoxy resins [4]-[9]. Tang et al. have reported that silicon carbon whiskerreinforced epoxy shows an increase of $13.8 \%-17.8 \%$ in flexural strength and also improves the thermal conductivity of composites [6]. Sudheer et al. have demonstrated that epoxybased composites reinforced with potassium titanate whisker (PTW) have improved tensile and flexural modulus [7]. In addition, Chen et al. have found that at the PTW content of $3 \mathrm{wt} \%$, the tensile strength of the composites reached maximum value [8]. The PTW has been discovered in 1979 with the commercial product's name of TISMO ${ }^{\circledR}$. The structure of PTW is a thin, crystalline fibre with the length of $10-20 \mu \mathrm{m}$ and the diameter of $0.3-0.6 \mu \mathrm{m}$. In addition, the price of PTWs is in the range of $1 / 10$ to $1 / 20$ of the cost of $\mathrm{SiC}$ whiskers [9]. It has been demonstrated that the PTW exhibits excellent friction and wear properties, which can improve the mechanical performance of epoxy resin in composite materials.

Herein, we report the mechanical performance of PTW-reinforced epoxy-based nanocomposites. The PTW-reinforced epoxy nanocomposites with different PTW loading were fabricated. The tensile strength, Young's modulus, micro-hardness and fracture 
behaviour were thoroughly evaluated. We expected that the more PTW was added, the higher the tensile strength, modulus and micro-hardness could be obtained.

\section{MATERIALS AND EXPERIMENTAL METHODS}

\subsection{Materials}

Low viscosity bisphenol-A epoxy resin (27-777, Refinetec Co., Japan) as a base resin and diethylenetriamine (DETA) (27-772, Refinetec Co., Japan) as a curing agent were purchased. Two types of PTWs were used as reinforcing fibre in the proposed nanocomposites. One was TISMO $^{\circledR} \mathrm{D}$ (TD), which are basic PTWs without any surface treatment and the other was TISMO $^{\circledR}$ D-102 (TD-102), which are silane-treated PTWs. These two PTWs were supplied by Otsuka Chemical Co., Ltd., Japan. The physical properties of TD and TD-102 are listed in Table 1.

\subsection{Preparation of nanocomposite specimens}

The desired amount of two kinds of PTWs (TD and TD-102) was added to epoxy. TD and TD-102 were individually added in the epoxy resin in the range of $1 \mathrm{wt} \%$ to $5 \mathrm{wt} \%$ and then the mixture was stirred for 24 hours at room temperature and under vacuum. The curing agent was added to the mixture and then the mixture was stirred for further half hour. The specimens of PTW/epoxy nanocomposites were prepared by using a silicone rubber mould (10 $\mathrm{mm} \times 100 \mathrm{~mm} \times 2 \mathrm{~mm}$, Fig. 1) and then cured at $50^{\circ} \mathrm{C}$ for 2 hours, followed by post curing at $100^{\circ} \mathrm{C}$ for 2 hours in an oven.

Table 1: Physical properties of TD and TD-102.

\begin{tabular}{|l|c|c|}
\hline Types of TISMO $^{\circledR}$ & D & D-102 \\
\hline Appearance & White needle crystal & White needle crystal \\
\hline Diameter $(\mu \mathrm{m})$ & $0.3-0.6$ & $0.3-0.6$ \\
\hline Length $(\mu \mathrm{m})$ & $10-20$ & $10-20$ \\
\hline Density $\left(\mathrm{g} / \mathrm{cm}^{3}\right)$ & 0.11 & 0.12 \\
\hline Water content $(\mathrm{wt} \%)$ & 0.17 & 0.07 \\
\hline Tensile strength $(\mathrm{GPa})$ & 7 & 7 \\
\hline Tensile modulus $(\mathrm{GPa})$ & 280 & 280 \\
\hline Mohs hardness & 4 & 4 \\
\hline
\end{tabular}

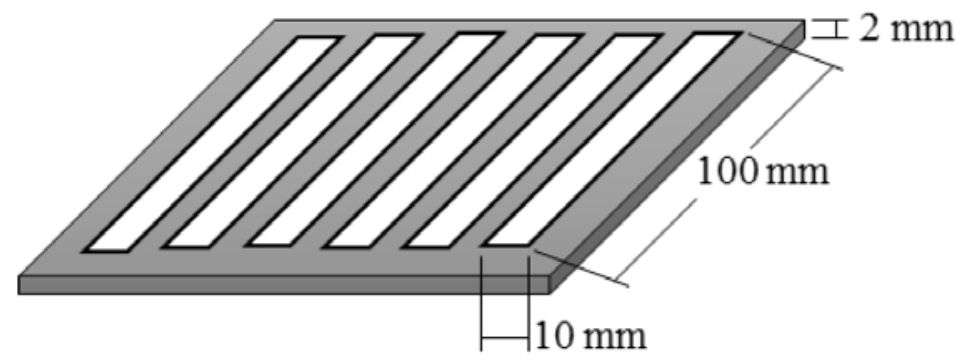

Figure 1: Silicone rubber mould for specimen fabrication. 


\subsection{Characterization of nanocomposite specimens}

The viscosity of the neat epoxy resin and the mixture of epoxy resin and PTW ( $1 \mathrm{wt} \%$ to 5 $\mathrm{wt} \%$ ) was measured by using a digital viscometer (DV-E, Brookfield Engineering Laboratories Inc., USA) at room temperature. The tensile properties of the PTW-reinforced nanocomposites were examined with a universal testing machine (5567, Instron Corporation, USA) at room temperature with a crosshead speed of $1.0 \mathrm{~mm} / \mathrm{min}$. The micro-hardness of the nanocomposite specimens was measured by using a hardness tester (GS-702G, Teclock Co., Japan) according to JIS K 7215. The morphology of fracture surfaces of the nanocomposites was observed by a field emission scanning electron microscope (S-4700, Hitachi Ltd., Japan).

\section{RESULTS AND DISCUSSION}

\subsection{Viscosity}

Table 2 shows variations of the viscosity in the neat epoxy resin and the mixture of epoxy resin and PTW. The viscosity of the epoxy/PTW mixture was higher than that of neat epoxy resin. This increasing trend is marked in the epoxy/PTW mixture with $4 \mathrm{wt} \%$ and $5 \mathrm{wt} \%$ loadings. Similar viscosity increases in fibre-reinforced nanocomposites were also reported elsewhere [10]. It should be noted that the viscosity of the epoxy/silane-treated PTW (TD102) mixture with $4 \mathrm{wt} \%$ and $5 \mathrm{wt} \%$ loading was lower than that of epoxy/untreated PTW (TD) mixture. It can be seen that the viscosity of both mixtures increased with increasing PTW loading.

\subsection{Micro-hardness}

The micro-hardness of the nanocomposites reinforced with TD and TD-102 increased by about $14 \%$ and about $19 \%$, respectively, compared to that of neat epoxy resin (Table 3). It can be seen that the addition of PTWs effectively increased the micro-hardness of the nanocomposites. This tendency was also reported in polystyrene-carbon nanotubes nanocomposites by Yang et al. [11]. Inherent higher rigidity of PTWs as shown in Table 1

Table 2: Viscosity of epoxy/PTW mixtures.

\begin{tabular}{|l|c|c|c|c|c|c|}
\hline & \multicolumn{6}{|c|}{ PTW (TD or TD-102) loading } \\
\cline { 2 - 7 } & $0 \mathrm{wt} \%$ & $1 \mathrm{wt} \%$ & $2 \mathrm{wt} \%$ & $3 \mathrm{wt} \%$ & $4 \mathrm{wt} \%$ & $5 \mathrm{wt} \%$ \\
\hline Viscosity of TD $(\mathrm{mPa} \cdot \mathrm{s})$ & 553 & 562 & 594 & 600 & 714 & 960 \\
\hline Viscosity of TD-102 $(\mathrm{mPa} \cdot \mathrm{s})$ & 553 & 612 & 615 & 648 & 692 & 834 \\
\hline
\end{tabular}

Table 3: Micro-hardness of epoxy/PTW nanocomposites.

\begin{tabular}{|l|c|c|c|c|c|c|}
\hline & \multicolumn{6}{|c|}{ PTW (TD or TD-102) loading } \\
\cline { 2 - 7 } & $0 \mathrm{wt} \%$ & $1 \mathrm{wt} \%$ & $2 \mathrm{wt} \%$ & $3 \mathrm{wt} \%$ & $4 \mathrm{wt} \%$ & $5 \mathrm{wt} \%$ \\
\hline $\begin{array}{l}\text { Micro-hardness of TD } \\
\text { nanocomposites }\end{array}$ & 70.8 & 73.3 & 78.7 & 79.7 & 80.3 & 80.8 \\
\hline $\begin{array}{l}\text { Micro-hardness of TD-102 } \\
\text { nanocomposites }\end{array}$ & 70.8 & 81.2 & 82.3 & 82.6 & 83.3 & 84.1 \\
\hline
\end{tabular}


seems to be responsible for this increase in micro-hardness in PTW-reinforced nanocomposites. When the same amount of TD or TD-102 was added to epoxy resins, the micro-hardness of the nanocomposites reinforced with TD-102 was higher than that of the nanocomposites reinforced with TD, possibly because the surface-treated TD-102 has better adhesion with epoxy resin than TD.

\subsection{Tensile properties}

The effect of PTW content on tensile strength and Young's modulus of TD-reinforced epoxy nanocomposites is depicted in Fig. 2. The neat epoxy had tensile strength of $24.9 \mathrm{MPa}$ and the maximum strength $(35.8 \mathrm{MPa})$ was observed at $1 \mathrm{wt} \%$ additive which is a $44 \%$ increase compared with that of neat epoxy. The tensile strength has gradually decreased from $2 \mathrm{wt} \%$ to $5 \mathrm{wt} \%$ of TD. The plausible explanation is that the TD with epoxy had poor interfacial adhesion, which leads to decrease in tensile strength. The tensile strength and Young's modulus of nanocomposites reinforced with TD-102 are shown in Fig. 3. The maximum tensile strength $(36.9 \mathrm{MPa})$ was also observed at $1 \mathrm{wt} \%$ addition. However, further increase in the amount of TD from $2 \mathrm{wt} \%$ to $5 \mathrm{wt} \%$ did not show significant changes.

\subsection{Fracture behaviour}

The fracture surface of TD/epoxy nanocomposite (TD content $=5 \mathrm{wt} \%$ ) is shown in Fig. 4. The PTWs are located on the fracture surface without any epoxy surroundings. This means that TD had poor interfacial adhesion with epoxy, and that this poor bonding led to the decrease in mechanical properties. The fracture surface of TD-102/epoxy nanocomposite (TD-102 content $=5 \mathrm{wt} \%$ ) is presented in Fig. 5. The PTWs were covered with epoxy resin. The interfacial adhesion between TD-102 and epoxy was much better than TD/epoxy, resulting in the improvement in their mechanical performances as indicated in Fig. 3.

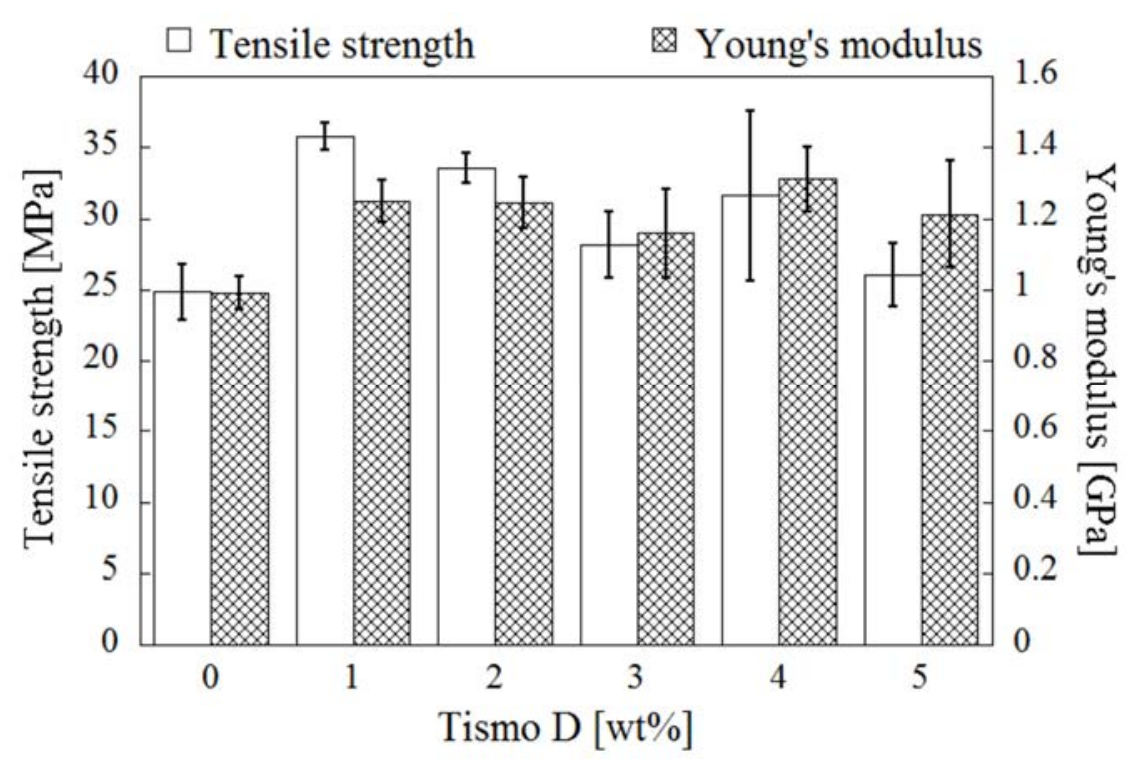

Figure 2: Mechanical properties of nanocomposites reinforced with TD. 


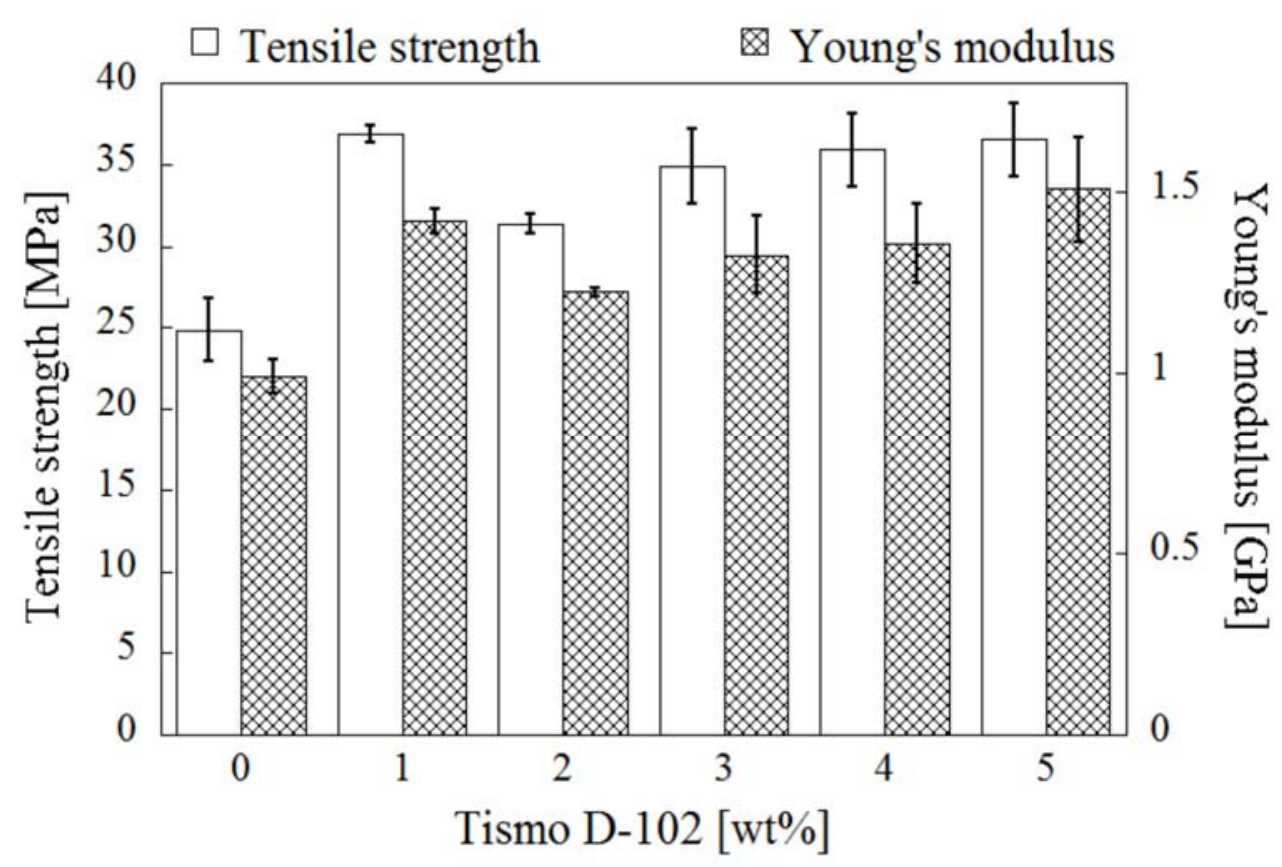

Figure 3: Mechanical properties of nanocomposites reinforced with TD-102.

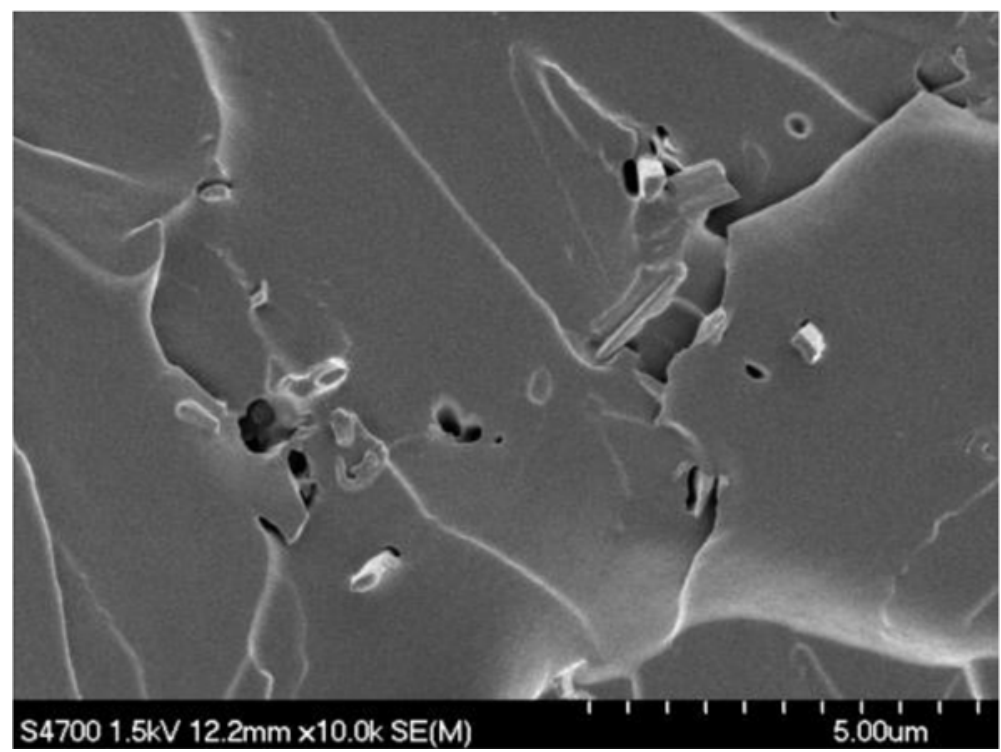

Figure 4: SEM micrograph of epoxy nanocomposite reinforced with $5 \mathrm{wt} \% \mathrm{TD}$. 


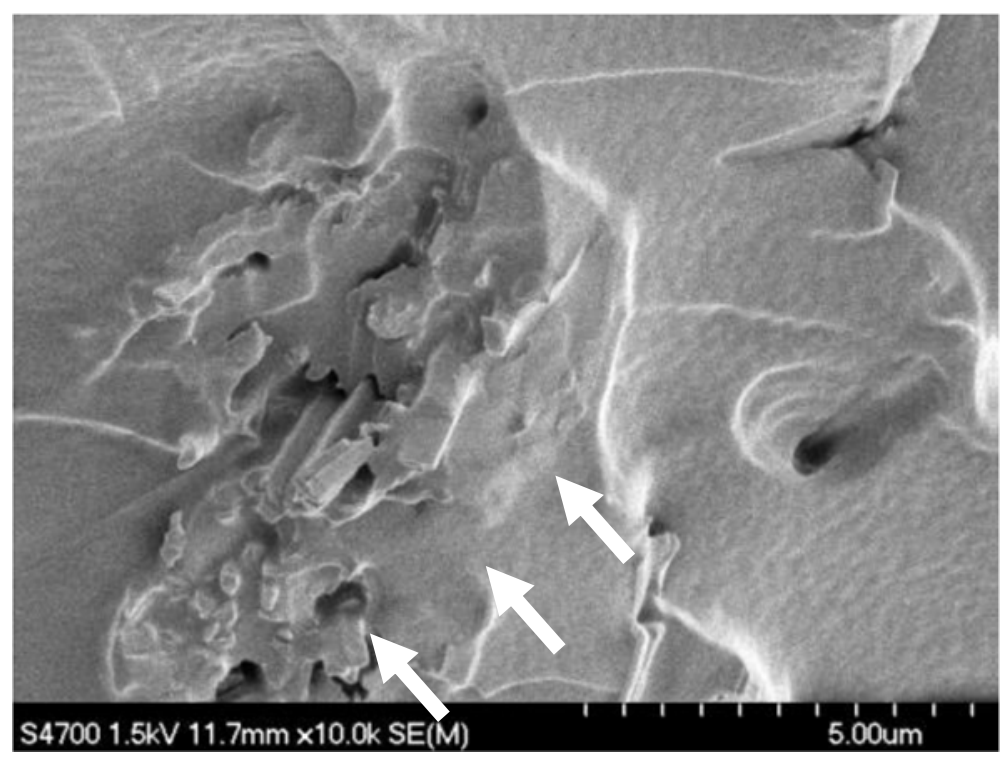

Figure 5: SEM micrograph of epoxy nanocomposite reinforced with 5 wt $\%$ TD-102. Arrows indicate PTWs covered with epoxy resin.

\section{CONCLUSIONS}

1. The reinforcing effect of PTW in mechanical performances of PTW nanocomposite system was confirmed experimentally. The tensile strength and Young's modulus of silane-treated PTW-reinforced nanocomposites increased with increasing silane-treated PTW loading.

2. The micro-hardness increased by about $14 \%$ in the PTW nanocomposites and $19 \%$ in silane-treated PTW nanocomposites, respectively, comparing with that of pristine epoxy resin, and this is due to the highly rigid property of PTW.

3. The scanning electron microscopy showed that the silane-treated PTWs (TD-102) were covered with matrix resin, which suggests the better interfacial adhesion between matrix resin and PTWs with the presence of silane coupling agent.

\section{ACKNOWLEDGEMENTS}

The authors are grateful to Professor Shih-Hsuan Chiu at National Taiwan University of Science and Technology for collaboration on the early stages of this research. We would like to thank Mr. Ueki and Mr. Sugano, Tokushima University, for technical assistance with SEM. We wish to thank Otsuka Chemical Co., Ltd. for providing the samples of potassium titanate whisker for this study.

\section{REFERENCES}

[1] Bauer, R.S. (ed.), Epoxy Resin Chemistry, Advances in Chemistry: Series 114, American Chemical Society: Washington, DC, p. 144, 1979.

[2] Pascault, J.P. \& Williams, R.J.J. (eds), Epoxy Polymers: New Materials and Innovations, Wiley-VCH: Weinheim, pp. 289-302, 2010. 
[3] Atta, A.M., Al-Lohedan, H.A., El-Saeed, A.M. \& Tawfeek, A.M., Effect of titanium dioxide nanogel surface charges and particle size on anti-corrosion performances of epoxy. International Journal of Electrochemical Science, 12, pp. 959-974, 2017.

[4] Fujii, K., Nakagaito, A.N., Takagi, H. \& Yonekura, D., Sulfuric acid treatment of halloysite nanoclay to improve the mechanical properties of PVA/halloysite transparent composite films. Composite Interfaces, 21(4), pp. 319-327, 2014.

[5] Sun, W.T., Takagi, H., Nakagaito, A.N. \& Chiu, S.H., Preparation and characterization of halloysite nanocomposites by rapid prototyping technology. Key Engineering Materials, 665, pp. 61-64, 2016.

[6] Tang, D. et al., Preparation and properties of epoxy/BN highly thermal conductive composites reinforced with SiC whisker. Polymer Composites, 37(9), pp. 1-11, 2016.

[7] Sudheer, M., Prabhu, R., Raju, K. \& Bhat, T., Effect of filler content on the performance of epoxy/PTW composites. Advances in Materials Science and Engineering, 2014, pp. 1-11, 2014.

[8] Chen, S., Wang, Q., Wang, T. \& Pei, X., Preparation, damping and thermal properties of potassium titanate whiskers. Materials and Design, 32(2), pp. 803-807, 2011.

[9] Suganuma, K., Fujuta, T., Niihara, K. \& Suzuki, N., AA6061 composite reinforced with potassium titanate whisker. Journal of Materials Science Letters, 8, pp. 808-810, 1989.

[10] Song, Y.S. \& Youn, J.R., Influence of dispersion states of carbon nanotubes on physical properties of epoxy nanocomposites. Carbon, 43(7), pp. 1378-1385, 2005.

[11] Yang, Z., Dong, B., Huang, Y., Liu, L., Yan, F.Y. \& Li, H.L., Enhanced wear resistance and micro-hardness of polystyrene nanocomposites by carbon nanotubes. Materials Chemistry and Physics, 94(1), pp. 109-113, 2005. 